\title{
Oral Health Perception and Practices among School Children Froma Low Socio Economic Locality in Mumbai, India.
}

\author{
Shrikala Acharya ${ }^{1}$, Nanda Pai $^{2}$,Jinal Vaghela ${ }^{3}$,Shubhangi Mankar ${ }^{4}$ \\ ${ }^{I}$ (Department of Community Medicine, Seth G. S Medical College And Kem Hospital, India) \\ ${ }^{2}$ (Department of Dentistry, Seth G. S Medical College And Kem Hospital, India) \\ ${ }^{3}$ (Department of Dentistry, Seth G. S Medical College And Kem Hospital, India) \\ ${ }^{4}$ (Department of Community Medicine, Seth G. S Medical College And Kem Hospital, India)
}

\begin{abstract}
Dental caries is the most common chronic disease of childhood that interferes with normal nutrition intake, speech, self-esteem and daily routine activities. Only sporadic data is available on the oral health condition in different states in India. In a metropolitan city like Mumbai, no systematic assessment on the oral health problems is available, especially among the children belonging to low socio-economic class, studying in municipal schools. Hence the current study was planned to provide the base line data of oral health perception and practices among the children studying in (V-VII Std.) suburban municipal school and predominantly from a low socio-economic area, located in the field practice area of a teaching medical college. The present cross sectional study was conducted among 299 school children of the age 9 to 13 years using a pre-tested semistructured questionnaire for face to face interview to assess their oral hygiene knowledge, perception and practices. Majority of the children were aware about importance of daily tooth brushing, avoidance of sweets especially at bedtime. Statistically significant association was found between awareness and practice of daily tooth brushing. Significantly more girls brushed their teeth daily. School oral health program to impart awareness about good oral habits needs to be implemented through all the schools.
\end{abstract}

Keywords: awareness, knowledge,oral habits, oral hygiene, perceptions, practices.

\section{Introduction}

Oral health is considered as an integral component of general health. It is highly essential to safeguard oral health right from the childhood otherwise; poor oral health will lead to various dental disorders and diseases which will adversely affect the overall health. Globally among children, dental caries is considered as one of the most important oral health problem. Dental caries is public health problem in India. It is one of the most prevalent oral health diseases in India. The prevalence is as high as $60-80 \%$ in Indian school children [1]. According to WHO 2003 Database, the mean DMFT Index at 12 years old ranges between 0.5 to 3.94 for Indian school going children. A nationwide survey of oral health conducted in 2004 throughout India, has shown that the prevalence of dental caries is $51.9 \%$ among five year old children, $53.8 \%$ among 12 year old children and $63.1 \%$ in 15 year old school children highlightingthat dental caries is a significant oral health disease[2].

It is evident that cultural beliefs and social taboos play an important role in the perception of the causes of dental decay and gum diseases. In many countries, the number of children brushing their teeth is very unsatisfactory including India. A small proportion of children do not clean their teeth at all. Some may not have access to a toothbrush and many use the traditional cleaning aids like datun, salt and oil, coal ash and locally made powders etc. A considerable population of children in the developing nations is being affected by tooth decay and most of the time, their proper treatment is given the last priority, owing to the limited access to oral health services. In a metropolitan city like Mumbai, no systematic assessment on the oral health problems is available, especially among the children belonging to low socio-economic class, studying in municipal schools. Hence the current study was planned to provide the base line data of oral health perception and practices among the children studying in (V-VII Std.) suburban municipal school and, predominantly from a low socio-economic area, located in the field practice area of a teaching medical college.

\section{Materials \& Methods}

The present Cross-sectional studywas conducted in a Municipal Public school located in MalwaniMalad, North Western Suburb of Mumbai city. The area predominantly consists of population from low socioeconomic class, engaged in various unorganised service sector. Mumbai Municipal Corporation, the local self-governance body provides for primary education and healthcare services in the community. There are two municipal secondary schools with a total of 574 students studying from class V to class VII.

Sample sizewas calculated using formula $4 \mathrm{pq} / 1^{2}[\mathrm{P}=$ prevalence of Dental caries among children $=54 \%$, $\mathrm{q}=100-\mathrm{p}=46 \%$ and allowable error $=5.8 \mathrm{]}$. Assuming $10 \%$ absenteeism \& unwillingness to participate in the study by the children, sample size was calculated as 321 . All the children studying in class V, VI, VII of the 
school, willing for participation with parents' written consent and present during the oral check-up were included in the study. A total of 299 students participated in the study.

Approval from Institutional Ethics committee and the school principalwas obtained for conducting the study. A parent's meeting was called, the purpose of the study was explained to the parents and their consent was taken.

Apre-tested semi-structured questionnaire was used for face to face interview with the children for assessment of oral hygiene knowledge, perception and practices. Plain mouth mirror, ice cream sticks, and probe was used for clinical oral examination by team of dental surgeons. Recording of oral health examination included dental caries status, other related oral health morbidities and DMFT index. All responses were tabulated using Microsoft-Excel 2007 Software for data analysis. Data was analysed by using SPSS software version 16.0. Statistical tools like mean, median, range, proportions and chi-square used as appropriate.

\section{Results}

In the study, $53.1 \%$ were boys and $46.9 \%$ were girls. Majority of the children were of 9 to 12 years and few children (10.4\%) were above 12 years"TABLE 1".95.7\%children agreed that daily brushing is a good habit, while $92.3 \%$ children perceived that eating sweets leads to dental caries.74.9\% children agreed that a person shouldavoid eating sweets at bedtime "TABLE 2". $77.6 \%$ children were brushing their teeth daily, of these, 59.2 $\%$ brushed their teeth once daily and $18.4 \%$ brushed twice a day. $62.5 \%$ of children brushed their teeth in the morning, $18.4 \%$ both in the morning and at night and the remaining children brushed their teeth at any time of the day. $80.9 \%$ used tooth brush with toothpaste for brushing their teeth. $14 \%$ used tooth powder while $5.1 \%$ applied Masheri (tobacco powder). $72.2 \%$ children mentioned eating sweets daily of these $20.7 \%$ ate at least once, $26.8 \%$ twice and $24.7 \%$ ate sweets more than twice daily. Only $40.1 \%$ children practised rinsing of mouth after the meals"TABLE 3". More girls $83.5 \%$ compared to boys $72.3 \%$ were brushing their teeth daily in our study. The difference is statistically significant $(\mathrm{p}<0.02)$. $80.5 \%$ boys and $81.5 \%$ girls used tooth brush. $72.9 \%$ boys and $71.5 \%$ girls ate sweets daily. The difference between the two genders is not significant. Almost the equal proportion of boys and girls rinsed their mouths after meal "TABLE 4"'Fig. 1".Among 272 children with the perception of daily brushing beinga good habit, $80.1 \%$ brushed their teeth daily. The association between perception and practice of daily tooth brushing is statistically significant ( $\mathrm{p}<0.001)$ "TABLE 5". $72.8 \%$ of children were eating sweets in spite of their awareness that it leads to dental caries. The association between the perception and the habit of eating sweets daily was not significant.

Table 1: age and sex wise distribution of children

\begin{tabular}{|l|l|l|l|l|}
\hline \multirow{2}{*}{ Age group } & Gender & \multirow{2}{*}{ Total } \\
\cline { 2 - 3 } & Male & Female & \multicolumn{2}{|l|}{} \\
\hline Age in Years & Frequency & Frequency & Frequency & Percent \\
\hline $\mathbf{9 - 1 0}$ & 50 & 54 & 104 & $34.8 \%$ \\
\hline $\mathbf{1 0 - 1 1}$ & 41 & 37 & 78 & $26 \%$ \\
\hline $\mathbf{1 1 - 1 2}$ & 52 & 34 & 86 & $28.8 \%$ \\
\hline $\mathbf{1 2 - 1 3}$ & 16 & 15 & 31 & $10.4 \%$ \\
\hline Total & $159(53.1 \%)$ & $140(46.9 \%)$ & 299 & $100 \%$ \\
\hline
\end{tabular}

Table 2: perceptions about oral hygiene habits

\begin{tabular}{|l|l|l|l|l|}
\hline \multirow{2}{*}{ Statements } & \multicolumn{2}{|c|}{ Agree } & \multicolumn{2}{c|}{ Disagree / Can't say } \\
\cline { 2 - 5 } & Frequency & Percent & Frequency & Percent \\
\hline Daily brushing is a good habit. & 286 & $95.7 \%$ & 13 & $4.3 \%$ \\
\hline $\begin{array}{l}\text { Eating Sweets leads to dental } \\
\text { caries }\end{array}$ & 276 & $92.3 \%$ & 23 & $7.7 \%$ \\
\hline $\begin{array}{l}\text { One should avoid eating sweets at } \\
\text { bedtime }\end{array}$ & 224 & $74.9 \%$ & 75 & $25.1 \%$ \\
\hline
\end{tabular}

Table 3: oral hygiene practices among children

\begin{tabular}{|l|l|l|l|l|l|}
\hline \multicolumn{2}{|l|}{ Oral Hygiene Practices } & \multicolumn{2}{l|}{ Yes } & Total & Percentage \\
\hline $\begin{array}{l}\text { Daily Brushing Of } \\
\text { Teeth }\end{array}$ & Once & 177 & \multirow{2}{*}{232} & 299 & $77.6 \%$ \\
\cline { 2 - 3 } & Twice & 55 & & \\
\hline Habit Of Using Tooth Brush & 242 & & 299 & $80.9 \%$ \\
\hline $\begin{array}{l}\text { Habit Of Eating Sweets } \\
\text { Daily }\end{array}$ & Once & 62 & 299 & $72.2 \%$ \\
\cline { 2 - 3 } & Twice & 80 & & \\
\cline { 2 - 3 } & $\begin{array}{l}\text { More } \\
\text { Than } \\
\text { Twice }\end{array}$ & 74 & & & \\
\hline Habit Of Rinsing Mouth After Meal & 120 & & 299 & $40.1 \%$ \\
\hline
\end{tabular}


Table 4: oral hygiene practices in both the genders

\begin{tabular}{|l|l|l|l|l|l|l|}
\hline $\begin{array}{l}\text { Oral Hygiene } \\
\text { Practices }\end{array}$ & \multicolumn{2}{|l|}{ Male (159) } & \multicolumn{2}{|l|}{ Female (140) } & \multirow{2}{*}{ Chi $^{2}$} & 'p' value \\
\cline { 2 - 7 } & Yes & & Yes & & \\
\hline $\begin{array}{l}\text { Daily brushing of } \\
\text { teeth }\end{array}$ & 115 & $72.3 \%$ & 117 & $83.5 \%$ & 0.681 & $\mathrm{p}<0.02$ \\
\hline $\begin{array}{l}\text { Habit of using } \\
\text { brush }\end{array}$ & 128 & $80.5 \%$ & 114 & 81.5 & 0.0044 & $\mathrm{p}>0.8$ \\
\hline $\begin{array}{l}\text { Habit of eating } \\
\text { sweets daily }\end{array}$ & 116 & $72.9 \%$ & 100 & 71.5 & 0.014 & $\mathrm{p}>0.36$ \\
\hline $\begin{array}{l}\text { Habit of rinsing } \\
\text { mouth after meal }\end{array}$ & 60 & $37.7 \%$ & 60 & 42.8 & 0.3465 & $\mathrm{p}>0.76$ \\
\hline
\end{tabular}

Figure 1:

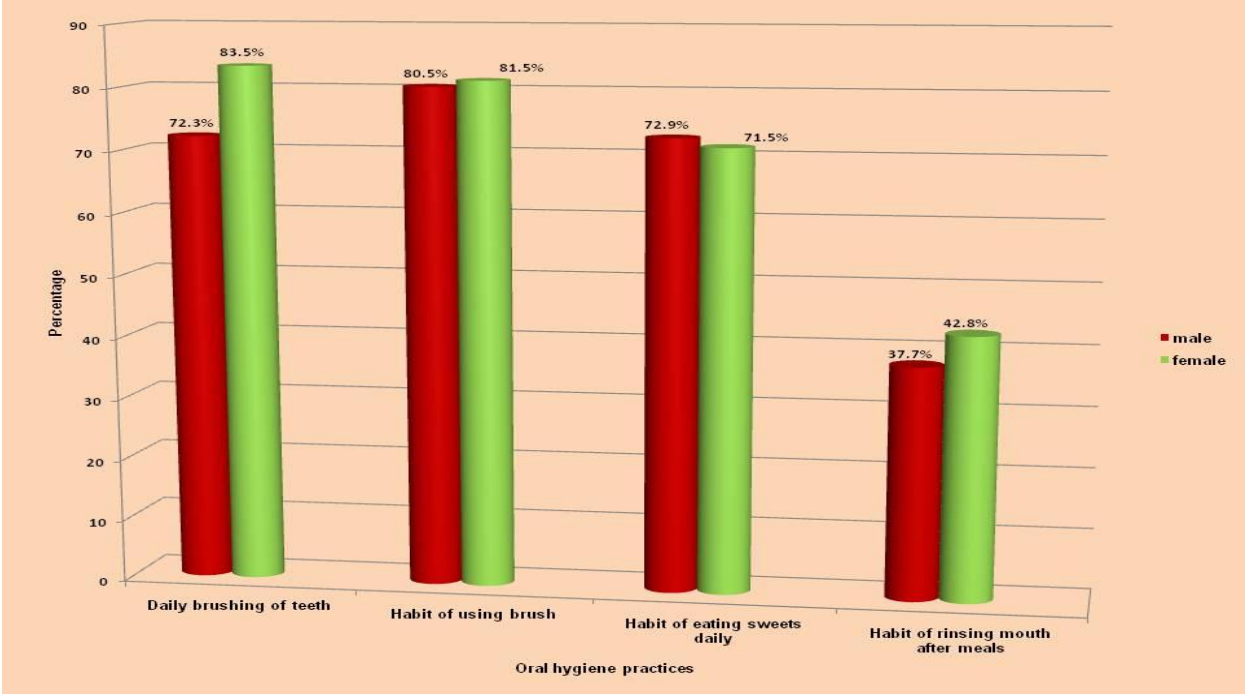

bar diagram showing oral hygiene practices among the children based on their gender.

Table 5: association between perception and practise of daily teeth brushing

\begin{tabular}{|l|l|l|l|l|l|l|}
\hline \multirow{2}{*}{$\begin{array}{l}\text { Daily Brushing } \\
\text { Is Good Habit }\end{array}$} & \multicolumn{4}{|c|}{ Brushing Teeth Daily } & \multicolumn{2}{c|}{ Total } \\
\cline { 2 - 7 } & Yes & No & \multicolumn{2}{c|}{ Number } & Percent \\
\cline { 2 - 7 } & Number & Percent & Number & Percent & Numb \\
\hline Yes & 218 & $80.1 \%$ & 54 & $19.8 \%$ & 272 & $91.0 \%$ \\
\hline No & 14 & $51.8 \%$ & 13 & $48.1 \%$ & 27 & $9.0 \%$ \\
\hline Total & 232 & $77.6 \%$ & 67 & $22.4 \%$ & 299 & $100.0 \%$ \\
\hline
\end{tabular}

\section{Discussion}

The current study assessed the Oral Health related knowledge, attitudes, and practices among 6-13 year old school children studying in Municipal public school in the North western region of Mumbai city. In India data about oral health of municipal school children from lower socioeconomic strata is not available hence this study was aimed to provide information and to assess the oral health needs of this population. Oral disease burden is significantly higher among poor and disadvantaged population with an increase in developing countries [3]. Especially in India dental caries affects more than four fifths of children between 6-19 years. Only a minor proportion of Indian school going children have good oral hygiene compared to larger population mong the developed countries [4, 5].Oral health promotions through schools is recommended by the World Health Organisation (WHO) for improving knowledge, attitudes and behaviour related to oral health and for prevention and control of dental diseases among school children[6].

In the present study $96 \%$ of the children believed that daily brushing is a good habit. Among them $80 \%$ practised daily teeth brushing. The association between perception and practice of daily teeth brushing was statistically significant. Girls $(84 \%)$ outnumbered boys in daily teeth brushing. These findings were comparable to the findings of Mehta et al. [6] El Qaderi et al. [7]Kuppuswamy et al. [8]. Almost 92.3\% believed that eating sweets lead to dental caries which was consistent with a study in Nigeria by Ogunrinde et al. [9] wherein consumption of sticky sugary and chocolaty food items were perceived as unhealthy to dental health. In our study $78 \%$ of children brushed their teeth using toothbrush and toothpaste which was in accordance to a study by Al-Omiri from Jordan [10] and other studies around the globe. About $18.4 \%$ of the children brushed their teeth twice daily and this was comparable to the study by Mehta A. et al. from Punchkula, India, however this 
was comparatively less than studies by Zhu et al. [11] and M. Priya et al. [12] in Chennai, India and Peng B et al. [13] from China.

\section{Conclusion}

Although the oral hygiene knowledge among the surveyed children was good, for its transformation into better oral health practices, re-emphasis through teachers and parents is recommended. School oral health program to impart awareness about good oral habits targeted at children aged 9 to 14 years including teacher and parentneeds to be implemented in all the schools in the country. In this, School teachers can be trained to emphasize oral health education and in regular monitoring of good oral health habits among school children. Awareness sessions should be conducted for parents on importance of oral health, oral hygiene practices and limiting sugar intake in the form of chocolates and candies among their children. Competitions and incentives for good oral health habits amongst school children can be one of the innovative ways for sustaining this behaviour change.

\section{References}

[1]. Vishal Chhabra.Dental Survey of Children in Ferozepur, India. Master of Dental Science, University of Sydney Australia; 2007.

[2]. Kumar A, Grewal H, Verma M. Prevalence of dental caries and treatment needs in the rural child population of Nainital District, Uttaranchal. Journal of Indian Society of Pedodontics and Preventive Dentistry 2009;27(4):224.

[3]. Lin S, Mauk A. Diseases in Rural India. Implementing Public Health interventions in developing countries. $105-129$.

[4]. Harikaran A G, Pallavi SK, Hariprakash S, Ashutosh, Nagesh KS. Oral Health - related KAP among 11 to 12 year old school children in a government - aided missionary school of Bangalore city. Indian Journal of Dental Research, 2008 ; $236-242$.

[5]. Grewal N, Kaur M. Status of oral Health awareness in Indian children as compared to Western children: A thought provoking situation (a pilot study). Journal of Indian Society of Pedodontics and Preventive Dentistry 2007; 25: 15-19.

[6]. Mehta A, Kaur G. Oral Health related knowledge, attitude and practices among 12 year old school children studying in rural areas of Panchkula, India. Indian Journal of Dental Research 2012; 23:293. Issue 2

[7]. El - Qaderi, Taani DQ. Oral health knowledge and dental health practices among school children in Jerah district -Jordan. Int J Dent Hyg 2004; 2:78-85.

[8]. VyshaleeKuppuswamy, Shruti Murthy, Shruti Sharma, Krishna M. Surapaneni, Ashoo Grover, Ashish Joshi. Oral hygiene status, knowledge, perceptions and practices among school settings in rural South India. Oral Health and Dental Management 2014 , 13 (1): 146-54.

[9]. Ogunrinde TJ, Oyewole OE, Dosumu OO. Dental care knowledge and practices among secondary school adolescents in Ibadan North Local Government Areas of Oyo State, Nigeria. European J Gen Dent 2015; 4:68-73.

[10]. Al-Omiri, Mahmoud K., Ahed M. Al-Wahadni, and Khaled N. Saeed. "Oral health attitudes, knowledge, and behavior among school children in North Jordan." Journal of dental education 70.2 (2006): 179-187.

[11]. Zhu L, Petersen PE, Wang HY, Bian JY, Jhang BX. Oral Health knowledge attitudes and behaviour of children and adolescents in China. Int Dent J. 2003;53: 289-98.

[12]. Priya M, Devdas K, Amarlal D, Venkatachalapathy A. Oral health attitudes, knowledge and practice among school children in Chennai, India. J Educ Ethics Dent 2013;3:26-33.

[13]. Peng B, Petersen PE, Fan MW, Tai BJ. Oral Health status and oral Health behaviour of 12 year old urban school children in the People's Republic of China. Comm. Dent Health 1997; 14: 238-44. 